\title{
Insulin-Like Growth Factor-I Is Necessary for Neural Stem Cell Proliferation and Demonstrates Distinct Actions of Epidermal Growth Factor and Fibroblast Growth Factor-2
}

\author{
Yvan Arsenijevic, ${ }^{1,2}$ Samuel Weiss, ${ }^{3}$ Bernard Schneider, ${ }^{1}$ and Patrick Aebischer ${ }^{1}$ \\ ${ }^{1}$ Division of Surgical Research and Gene Therapy Center, Pavillon 4 Centre Hospitalier Universitaire Vaudois, 1004 \\ Lausanne, Switzerland, 2Unit of Oculogenetic, Eye Hospital Jules Gonin, 1004 Lausanne, Switzerland, and ${ }^{3}$ Genes and \\ Development Research Group, Department of Cell Biology and Anatomy, University of Calgary Faculty of Medicine, \\ Calgary, Alberta, Canada T2N 4N1
}

Neural stem cells (NSCs), when stimulated with epidermal growth factor (EGF) or fibroblast growth factor-2 (FGF-2), have the capacity to renew, expand, and produce precursors for neurons, astrocytes, and oligodendrocytes. We postulated that the early appearance of insulin-like growth factor (IGF-I) receptors during mouse striatum development implies a role in NSC regulation. Thus, we tested in vitro the action of IGF-I on the proliferation of striatal NSCs. In the absence of IGF-I, neither EGF nor FGF-2 was able to induce the proliferation of E14 mouse striatal cells. However, addition of IGF-I generated large proliferative clusters, termed spheres, in a dose-dependent manner. The newly generated spheres were multipotent, and clonal analysis revealed that EGF or FGF-2, in the presence of IGF-I, acted directly on NSCs. The actions of IGF-I suggest distinct modes of action of EGF or FGF-2 on NSCs. First, continuous versus delayed administration of these neurotrophic factors showed that neither IGF-I nor EGF had an effect on NSC survival, whereas FGF-2 promoted the survival or maintenance of the stem cell state of $50 \%$ of NSCs for $6 \mathrm{~d}$. Second, shortterm exposure to IGF-I induced the proliferation of NSCs in the presence of EGF, but not of FGF-2, through an autocrine secretion of IGF-I. These findings suggest that IGF-I is a key factor in the regulation of NSC activation and that EGF and FGF-2 control striatal NSC proliferation, in part, through distinct intracellular mechanisms.

Key words: neurogenesis; neural stem cells; striatum; FGF-2; survival; autocrine regulation
The in vitro study of neural stem cells (NSCs) (Reynolds et al., 1992; Reynolds and Weiss, 1996; Palmer et al., 1997; Shihabuddin et al., 1997) is a potent tool for delineating the actions of epigenetic and intrinsic factors on precursors for neurons (Ahmed et al., 1995; Johe et al., 1996; Arsenijevic and Weiss, 1998; Shimazaki et al., 1999), astrocytes (Gross et al., 1996; Marmur et al., 1998), and oligodendrocytes (Hammang et al., 1997; Ben-Hur et al., 1998; Zhang et al., 1998). Recent in vitro studies of NSCbased neurogenesis and gliogenesis suggest that these processes occur by stepwise restriction and are dependent on environmental signals (Vescovi et al., 1993; DeHamer et al., 1994; Ahmed et al., 1995; Kalyani et al., 1997; Mehler and Kessler, 1997; Palmer et al., 1997; Rao and Mayer-Proschel, 1997; Arsenijevic and Weiss, 1998). Control of NSC proliferation depends on the actions of epidermal growth factor (EGF) and/or its homolog transforming growth factor- $\alpha$, basic fibroblast growth factor (FGF-2), and the p75 receptor (Reynolds et al., 1992; Morshead et al., 1994; Craig et al., 1996; Kalyani et al., 1997; Tropepe et al., 1997, 1999). Moreover, several studies have shown that NSCs can be isolated from different regions of the CNS during very early

Received Jan. 17, 2001; revised June 12, 2001; accepted July 6, 2001.

This work was supported by the Swiss National Science Foundation, the Ott Foundation, and the Canadian Institutes of Health Research. S.W. is an Alberta Heritage Foundation for Medical Research Scientist. We thank Dr. William Biancobose for critical reading of an earlier version of this manuscript and Meriem Tekaya, Dorothea Livingstone, and Dana Hornfeld for their technical assistance.

Correspondence should be addressed to Dr. Yvan Arsenijevic, Unit of Oculogenetic, Ophthalmic Hospital Jules Gonin, 15 av. de France, 1004 Lausanne, Switzerland. E-mail: Yvan.Arsenijevic@chuv.hospvd.ch

Copyright (C) 2001 Society for Neuroscience $\quad 0270-6474 / 01 / 217194-09 \$ 15.00 / 0$ development with FGF as the mitogen but not with EGF (Kalayani et al., 1999; Tropepe et al., 1999; Zhu et al., 1999; Qian et al., 2000). NSCs become responsive to EGF at a later developmental stage (Tropepe et al., 1999; Zhu et al., 1999). For cortical progenitor cells, an increase in EGF receptors during development appears to regulate the acquisition of EGF responsiveness (Burrows et al., 1997; Lillien and Raphael, 2000), and this may be modulated by different diffusible factors (Lillien and Raphael, 2000). For instance, in the presence of EGF, fewer cortical NSCs could be generated from the cortex at embryonic day (E) 12 in comparison to E15. And coculture of E15 cortical cells with E12 cells decreased the number of NSCs that could be generated from E15 cells, suggesting that a diff usible factor at E12 prevented the activation of NSCs (Lillien and Raphael, 2000). The inhibiting factor was identified as the bone morphogenetic protein-4 (BMP4), which is present in the cortex during early development.

We hypothesized that other factors may be involved in the control of NSC proliferation. The insulin-like growth factor-I (IGF-I) receptor family is evolutionarily conserved from invertebrates to mammals, and IGF-I receptors are present throughout the CNS during embryogenesis. IGF-II and IGF-I are expressed during brain development and are believed to act on virtually all neural cells (Petruzelli et al., 1986; Garofalo and Rosen, 1988; LeRoith et al., 1988; Stylianopoulou et al., 1988; Bassas et al., 1989; Bondy et al., 1990; Bartlett et al., 1991; Bondy, 1991; Garcia-Segura et al., 1991; Devaskar et al., 1993; Kar et al., 1993). The IGF-I receptors are expressed in germinal regions that colocalize both EGF receptors and the FGF-receptor-1 (FGFR-1). Considering that IGF family members play an important role in 


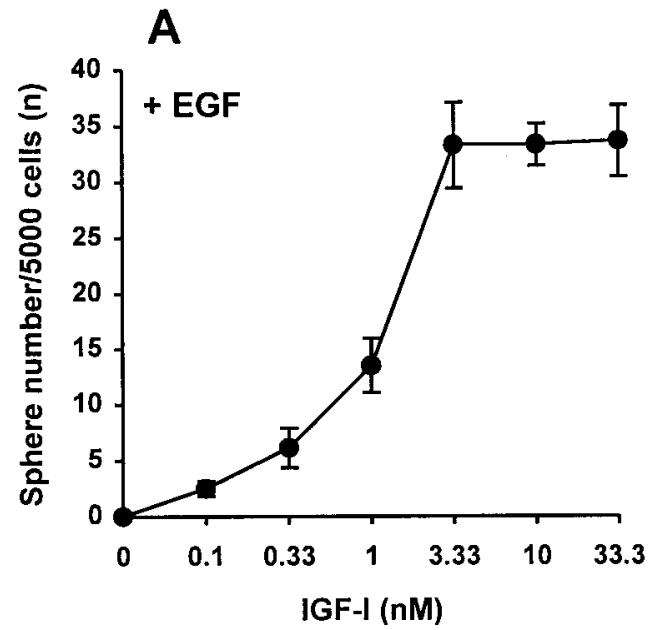

telencephalic development (de Pablo and de la Rosa, 1995), we hypothesized a possible interaction between EGF, FGF-2, and IGF-I on NSC regulation. Our results revealed that IGF-I is necessary for the action of EGF and FGF-2 in inducing the proliferation and expansion of striatal NSCs. In addition, we found that EGF and FGF-2 have different modes of actions on NSCs, including the transduction of intracellular signals.

\section{MATERIALS AND METHODS}

Primary culture and sphere passaging. Ganglionic eminences were removed from 14-d-old BALB/c mouse embryos (IFFA Credo, L'Arbresle, France) in PBS buffer containing $0.6 \%$ glucose, penicillin $(50 \mathrm{U} / \mathrm{ml})$, and streptomycin $(50 \mathrm{mg} / \mathrm{ml})$ (both from Life Technologies, Paisley, Scotland). Tissue was mechanically dissociated with a fire-polished pipette in serum-free medium composed of a 1:1 mixture of DMEM and F-12 nutrient (Life Technologies). Cells were grown in growth medium in 96-well plates (Falcon; Becton Dickinson, Franklin Lakes, NJ) at a concentration of 5,000 cells per $200 \mu \mathrm{l}$. The growth medium contained DMEM and F-12 nutrient (1:1), glucose (0.6\%), glutamine (2 mM), sodium bicarbonate (3 $\mathrm{mm})$, and HEPES buffer $(5 \mathrm{~mm})$, transferrin (100 $\mathrm{mg} / \mathrm{ml})$, progesterone $(20 \mathrm{nM})$, putrescine $(60 \mu \mathrm{M})$, and selenium chloride (30 nM) (all from Sigma, St. Louis, MO, except glutamine from Life Technologies), and EGF or FGF-2 (20 ng/ml; PeproTech, Rocky Hill, $\mathrm{NJ})$. The number of spheres was counted after $8-10 \mathrm{~d}$ in vitro (DIV). Six to eight wells per condition tested were counted.

Propagation of single spheres. Single spheres were evaluated for their capacity to renew and expand. Individual spheres were transferred to 1.5 $\mathrm{ml}$ microtubes containing $200 \mu \mathrm{l}$ of the growth medium. Single spheres were dissociated by mechanical action. Dissociated cells were then plated in a 96-well plate and incubated for $10 \mathrm{DIV}$ in the presence of various growth factors.

Differentiation of spheres. After 8-10 DIV, the spheres were transferred individually and plated onto poly-L-ornithine coated coverslips in 24-well plates (Falcon; Becton Dickinson). Each well contained five spheres and $1 \mathrm{ml}$ of the above-mentioned medium with insulin $(25 \mu \mathrm{g} / \mathrm{ml})$ and $1 \%$ fetal bovine serum (FBS), but no EGF or FGF-2. Spheres were fixed after 7 DIV.

Antibodies. Primary antibodies for indirect immunocytochemistry included (final dilution, source): mouse $\mathrm{IgG}$ monoclonal antibody to $\beta$-tubulin isotype III (1:1000; Sigma, Buchs, Switzerland), rabbit antiserum to GFAP (1:400; Dako, Glostrup, Denmark), mouse IgM monoclonal antibody to O4 (1:20; Roche Diagnostics, Rotkreuz, Switzerland). Secondary antibodies (Jackson ImmunoResearch, West Grove, PA) were as follows: cyanine-conjugated affinity-purified goat antibody to mouse IgG (1:1000), fluorescein-conjugated affinity-purified goat antibody to mouse $\operatorname{IgG}(1: 100)$, and Coumarin (AMCA)-conjugated affinity-purified goat antibody to mouse IgM (1:100).

Immunocytochemistry and cell counting. Indirect immunochemistry using secondary antibodies conjugated to rhodamine, fluorescein, or AMCA was performed on cells $7 \mathrm{~d}$ after plating as previously described (Arsenijevic and Weiss, 1998). In brief, coverslips were fixed with $4 \%$ paraformaldehyde for $20 \mathrm{~min}$ and washed three times successively with
PBS for $5 \mathrm{~min}$ each time. For triple-labeling experiments, primary antibodies (anti- $\beta$-tubulin, 1:1000, and anti-GFAP, 1:400) were diluted in PBS containing $10 \%$ normal goat serum and $0.3 \%$ Triton $\mathrm{X}-100$. Coverslips were incubated for $2 \mathrm{hr}$ at $37^{\circ} \mathrm{C}$ and then washed three times with PBS as above. Cyanine- and fluorescein-conjugated secondary antibodies to mouse and to goat $\mathrm{IgG}$, respectively, were added. The cells were incubated for $30 \mathrm{~min}$ at $37^{\circ} \mathrm{C}$. After three $5 \mathrm{~min}$ PBS washes, slips were incubated with IgM primary antibodies against $\mathrm{O} 4$ for $2 \mathrm{hr}$ at $37^{\circ} \mathrm{C}$. The coverslips were washed again three times and incubated $30 \mathrm{~min}$ with AMCA-conjugated secondary antibody to mouse IgM. Finally, the cells were washed twice with PBS, and then Hoechst (1 mg/ml; Sigma) was added for $15 \mathrm{~min}$ at room temperature, followed by two more PBS rinses of $5 \mathrm{~min}$ each. A rapid water wash preceded the mounting on glass slides with Fluorsave (Calbiochem, Darmstadt, Germany). Then, fluorescence was detected and photographed with an Olympus BX40 photomicroscope (Olympus Optical, Tokyo, Japan).

Immunoreactive cells for $\beta$-tubulin, GFAP, O4, or fluorescent nuclei from Hoechst labeling were counted blind. Unpaired $t$ tests were used to distinguish differences between experiments, and paired $t$ tests were used to compare conditions within an experiment. All results are expressed as a mean \pm SEM.

\section{RESULTS}

\section{Neural stem cell proliferation stimulated by EGF or FGF-2 requires the presence of IGF-I}

Murine embryonic striatal NSCs can be isolated in vitro by inducing their proliferation with either EGF (Reynolds et al., 1992) or FGF-2 (Qian et al., 1997; Ciccolini and Svendsen, 1998; Tropepe et al., 1999). The resulting proliferation generates a large cell cluster that is termed a sphere or neurosphere. Each sphere originates from one cell, and thus the presence of a sphere attests to the presence of a stem cell (Reynolds and Weiss, 1996). Primary germinal zone cells from the striatum (ganglionic eminences) of the E14 mouse embryo were plated into single wells of a 96-well plate in the presence of growth factors. The number of spheres was then counted after 8-10 DIV. Thus, primary E14 striatal cells were plated at low density (see Material and Methods) in the presence of EGF or FGF-2 and increasing doses of IGF-I. In the absence of IGF-I, no spheres were observed. However, IGF-I induced a dose-dependent increase in sphere number with either EGF or FGF-2 (Fig. 1). The concentration at which IGF-I is maximally effective, $\sim 3 \mathrm{nM}$, corresponded to the $K_{\mathrm{d}}$ of the IGF-I receptor (LeRoith et al., 1993) and indicates that physiological IGF-I concentrations are effective in promoting sphere formation by EGF or FGF-2. However, it remained necessary to establish and confirm that these spheres were generated by NSCs. Because there are no markers available to unambiguously distinguish NSCs from the other progeny generated in 
Table 1. EGF + IGF-I and FGF-2 + IGF-I generated spheres are multipotent

\begin{tabular}{|c|c|c|c|c|c|c|c|}
\hline \multirow[b]{2}{*}{ Spheres } & \multicolumn{2}{|l|}{$\underline{\text { Proliferation }}$} & \multicolumn{5}{|c|}{ Differentiation (spheres/total spheres) } \\
\hline & Sphere $\mathrm{I}^{\mathrm{o}}(n)$ & Renewing & NAO & NA & A & $\mathrm{AO}$ & $\mathrm{O}$ \\
\hline \multirow[t]{2}{*}{$\mathrm{E}+\mathrm{IGF}-\mathrm{I}$} & $70 \pm 19$ & $(29 / 33)$ & $62 / 97$ & $26 / 97$ & $6 / 97$ & $5 / 97$ & $1 / 97$ \\
\hline & & & $64 \%$ & $27 \%$ & $6 \%$ & $5 \%$ & $1 \%$ \\
\hline \multirow[t]{2}{*}{$\mathrm{E}+$ IGF-I $24 \mathrm{hr}$} & $46 \pm 9.4$ & $(29 / 33)$ & $61 / 96$ & $25 / 96$ & $4 / 96$ & $5 / 96$ & $1 / 96$ \\
\hline & & & $62 \%$ & $26 \%$ & $4 \%$ & $5 \%$ & $1 \%$ \\
\hline \multirow[t]{2}{*}{$\mathrm{F}+\mathrm{IGF}$} & $56 \pm 6.3$ & $(69 / 77)$ & $68 / 89$ & $20 / 89$ & & $1 / 89$ & \\
\hline & & & $76 \%$ & $23 \%$ & & $1 \%$ & \\
\hline
\end{tabular}

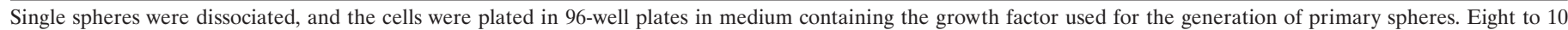

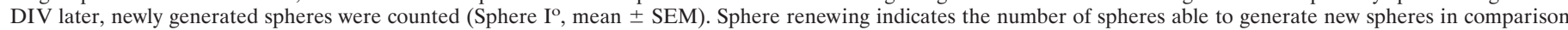

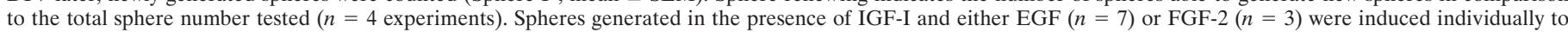

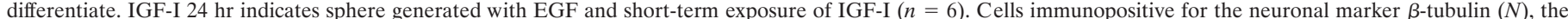

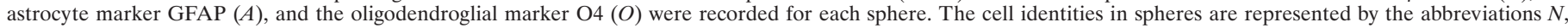
$A$, and $O$. The percentage of a specific sphere type in comparison to the whole population analyzed is indicated in each column. Sphere $I^{O}$, primary source.

Figure 2. FGF-2 + IGF-I and EGF + IGF-I generated spheres are multipotent. Single spheres were individually transferred to culture wells and exposed to conditions that favor cell differentiation (see Materials and Methods). The majority of the analyzed spheres that were generated by either FGF-2 $(A-C)$ or EGF $(D-F)$ (Table 1) contained cells immunoreactive for the neuronal marker $\beta$-tubulin $(A, D$, arrows), the astrocyte marker GFAP $(B$, arrow$h e a d)$, and the oligodendrocyte marker O4 $(F$, arrowhead). Magnification, $400 \times$.
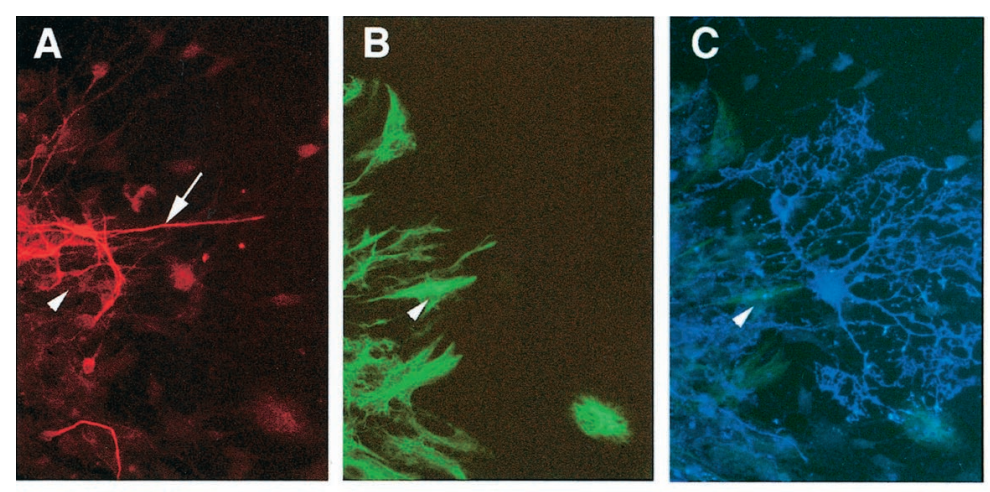

FGF-2+IGF-I sphere
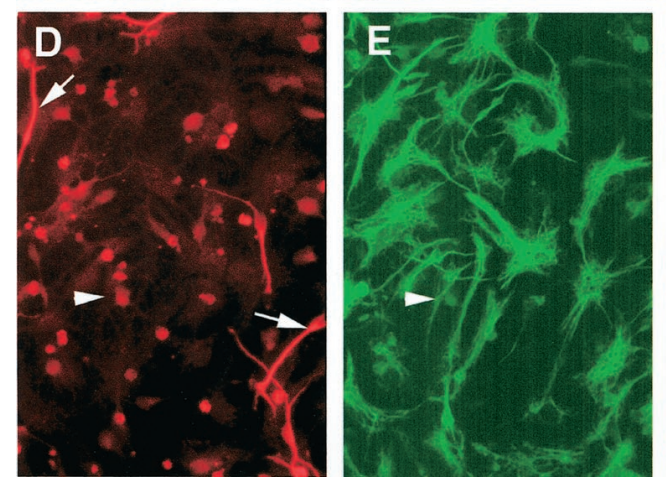

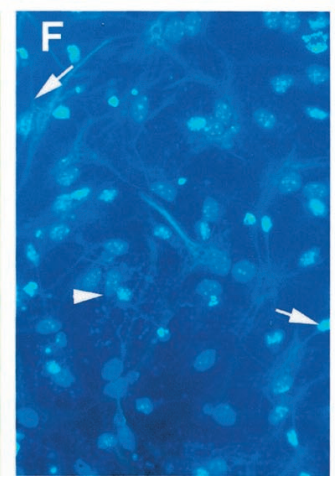

\section{EGF+IGF-I sphere}

secondary spheres (Table 1). No obvious differences between EGF + IGF-I- and FGF-2 + IGF-I-generated spheres were observed.

From these experiments, IGF-I, together with EGF or FGF-2, appeared to be sufficient to maintain NSC renewal. To determine whether EGF + IGF-I and FGF-2 + IGF-I spheres were multipotent, single spheres were transferred onto coverslips coated with poly-L-ornithine in a medium containing 1-2\% of FBS (no EGF or FGF-2) to promote cell differentiation. After 7 DIV, the spheres were fixed and stained by triple immunocytochemistry to reveal neurons, astrocytes, and oligodendrocytes. In seven experiments with EGF + IGF-I spheres, 64\% of the 97 spheres examined were multipotent, and 94\% contained neurons and astrocytes (Fig. 2, Table 1). Furthermore, 76\% (68 of 89) of the FGF-2 + IGF-I spheres were multipotent $(n=3)$, and $99 \%$ produced neurons and astrocytes. Thus, IGF-I in the presence of EGF or FGF-2 was necessary and sufficient to maintain self-renewal as well as multipotentiality of striatal NSCs.

Because IGF-I receptors are ubiquitous, the action of IGF-I on corresponded to $83 \%$ of the total spheres analyzed. Ninety percent of FGF-2 + IGF-I primary spheres were able to generate 

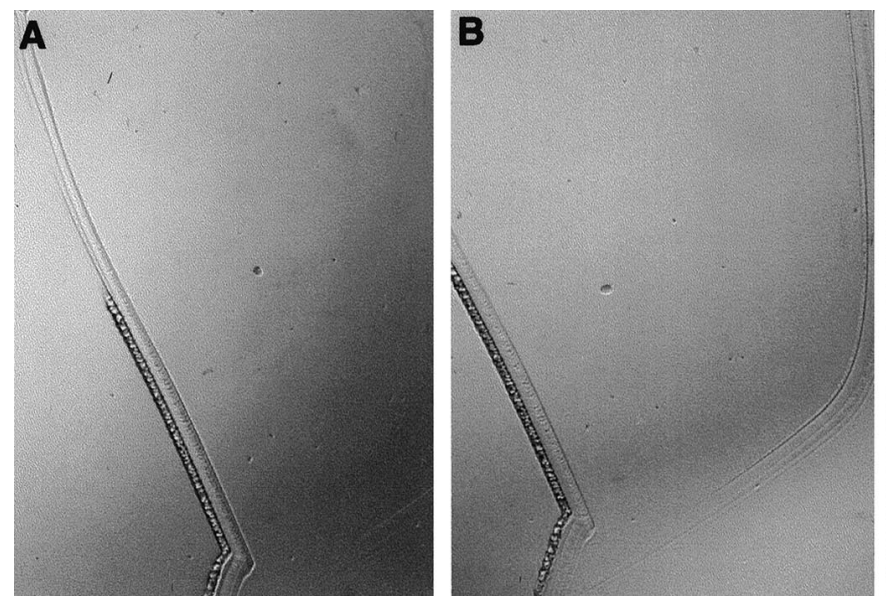

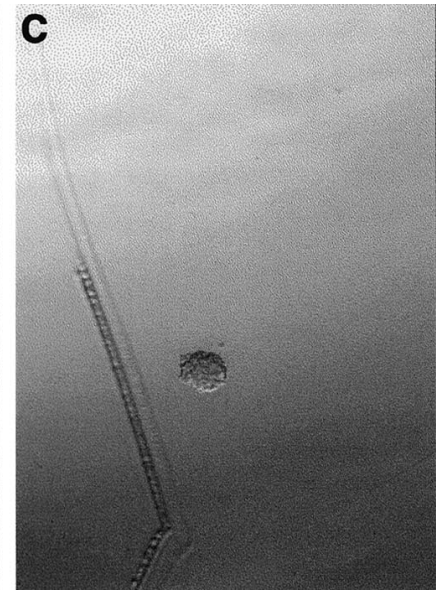

Figure 3. Clonal analysis reveals a direct action of IGF-I on NSCs. The effect of EGF and IGF-I was tested with striatal E14 cells that were plated at clonal density (30-150 cells per 96 -well plate). Cells were followed continuously. Between 2 and 5 DIV, rare cells enlarged $(A)$ and divided $(B)$ to form a sphere (C) after 10-15 DIV. Similar observations were made for cells responsive to IGF-I + FGF-2 (data not shown) (Table 2). Magnification, $400 \times$.

\begin{tabular}{|c|c|c|c|}
\hline $\begin{array}{l}\text { Experiment } \\
\text { number and } \\
\text { condition }\end{array}$ & $\begin{array}{l}\text { Cell concentration } \\
\text { (cells/well) }\end{array}$ & $\begin{array}{l}\text { Total number } \\
\text { of cells } \\
\text { plated }\end{array}$ & $\begin{array}{l}\text { Sphere } \\
\text { number }\end{array}$ \\
\hline 1. $\mathrm{E}+\mathrm{I}$ & 103 & 39,552 & 75 \\
\hline 2. $\mathrm{E}+\mathrm{I}$ & 147 & 119,544 & 163 \\
\hline 3. $\mathrm{E}+\mathrm{I}$ & 64 & 18,432 & 38 \\
\hline 4. $F+I$ & 26 & 6,838 & 15 \\
\hline 5. F + I & 20 & 3,816 & 8 \\
\hline 6. F+I & 29 & 5,684 & 4 \\
\hline
\end{tabular}

E14 striatal cells were plated at clonal density in 96-well plates in the presence of IGF-I and EGF or FGF-2. To determine cell concentration, all cells contained in a well were counted after plating ( 8 wells per experiment were checked). For each experiment, the total number of cells plated is given in the third column (for the first experiment a total of 39,552 cells were plated in 384 wells at a density of 103 cells per well). At 10 DIV, the total number of spheres was counted for the total of cells plated. $E$, EGF; $F$, FGF-2; I, IGF-I.

NSC s could be mediated by other cells via an unknown factor. To verify a direct action of IGF-I on NSCs, striatal neural stem cell proliferation was examined at clonal density. The cell numbers ranged between 64 and 147 cells per well for experiments testing the effect of IGF-I + EGF, and 20-29 cells per well for studies with IGF-I + FGF-2. A total of 177,528 cells were analyzed from three different experiments for EGF + IGF-I studies, and 16,338 cells were analyzed for FGF-2 + IGF-I. In parallel experiments, cells were plated at 5,000 cells per well. In all experiments, EGF + IGF-I or FGF-2 + IGF-I were able to generate spheres at clonal density (Fig. 3, Table 2). For example, in one representative experiment, at a clonal density of $64 \pm 5$ cells per well, 38 spheres were observed from a total of 18,432 cells plated in 288 wells. The growth rate was partially decreased (data not shown). These experiments indicated that IGF-I and EGF or FGF-2 act directly on NSCs.

\section{FGF-2 promotes the survival or maintains the undifferentiated state of NSCs, whereas EGF and IGF-I do not}

To begin to define the interactions and functions of IGF-I, EGF, and FGF-2 in NSC proliferation and sphere formation, the putative survival action of each of these factors was tested. We define survival to be a dependence on the presence of a factor throughout the culture period. For example, if IGF-I is a survival factor for NSCs, its constant presence, starting at plating time, should allow for NSC proliferation regardless of when EGF is introduced. Thus, IGF-I was added at plating and was present during the entire cell culture period. Then, EGF was added either at plating or at 3 or 5 DIV. Delayed administration of EGF was not able to produce the same number of spheres generated when both IGF-I and EGF were present starting at plating (Fig. 4B). The loss of sphere number corresponds to $\sim 90 \%$. The reverse experiment, with the constant presence of EGF, similarly produced only a small number of spheres when IGF-I was delayed and only added at 3 or 5 DIV. This series of experiments showed that IGF-I and EGF had weak, if any, survival actions on NSCs. Another possibility is that NSCs differentiated with either IGF-I or EGF alone. On the other hand, the constant presence of FGF-2 starting at plating allowed sphere formation when IGF-I was added at 4 or 6 DIV. Approximately $50 \%$ of striatal NSCs survived and could still be induced to proliferate at later time points, having been maintained in the sole presence of FGF-2 (Fig. 4C). These experiments suggest that a component of the actions of FGF-2 is to promote the survival of NSCs or to enhance the maintenance of their undifferentiated state.

\section{FGF-2 and EGF likely act on the same striatal neural stem cells}

The fact that NSCs can be generated either by EGF + IGF-I or by FGF-2 + IGF-I leads us to consider whether these factors act on the same cells, or on two separate populations. First, we compared the number of spheres generated in the presence of IGF-I + EGF, IGF-I + FGF-2, and IGF-I + EGF + FGF-2. If two populations of NSCs exist, an additive action of EGF and FGF-2 should occur. We found that the absolute number of spheres generated in the presence of IGF-I + EGF was not very different from the number generated with IGF-I + FGF-2 (Fig. 1). The co-incubation of the three factors (IGF-I, EGF, FGF-2) produced a similar number of spheres to those generated by the stimulation of IGF-I + EGF or IGF-I + FGF-2 $(n=5)$ (Fig. 5). These data suggest that EGF and FGF-2 likely act on the same NSCs. To further test this, we hypothesized that during the first 4 DIV, FGF-2 will allow the survival of NSCs (as illustrated in Fig. 4) that should, in turn, be responsive to the subsequent actions of EGF and IGF-I. This was indeed the case, and the results are shown in Figure 5. When NSCs were incubated in FGF-2 for 4 DIV, the cells were washed, and EGF + IGF-I was added, the same number of spheres was generated as was produced in the constant presence of FGF-2 and IGF-I. 
A

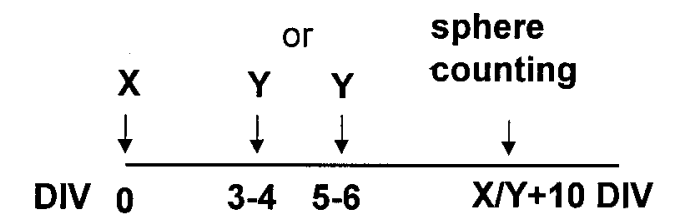

B

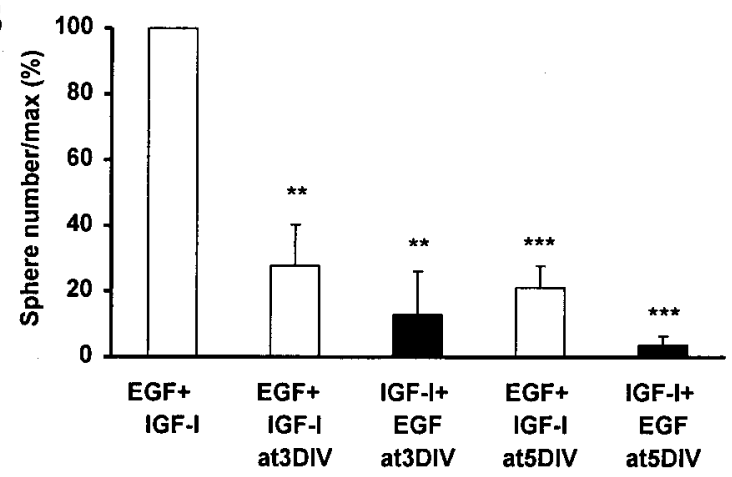

C

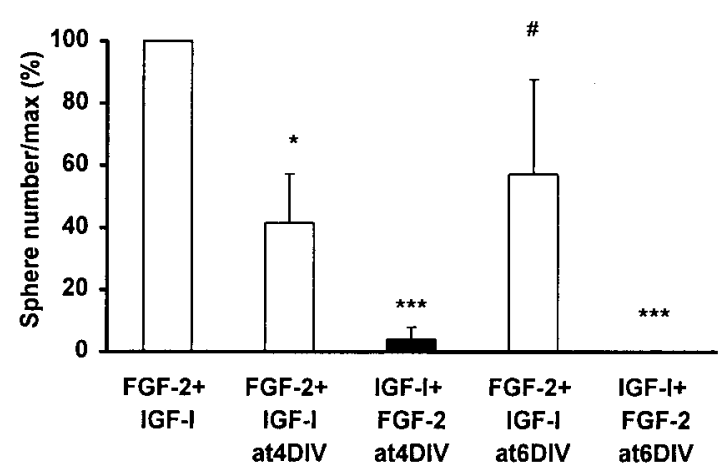

Figure 4. FGF-2 maintains in vitro the presence of embryonic striatal NSCs. $A$, To test the possible survival effect of EGF or IGF-I on primary E14 striatal cells, one factor was present during the whole experimental period, whereas the other was administered 3-4 or 5-6 d after plating, and the spheres were counted 8-10 DIV after the final addition. For cell density conditions, see the legend to Figure 1. The co-incubation of EGF + IGF-I beginning at plating served as control. $B$, All delayed administrations of EGF or IGF-I resulted in a significant decrease in sphere number in comparison to the control group $(B ; n=5)$. $C$, The constant presence of FGF-2 sustained NSC survival or the NSC state for at least 6 $\operatorname{DIV}(B ; n=3-5) .{ }^{*} p<0.05,{ }^{*} p<0.01,{ }^{* * *} p<0.001, \# p=0.2$, in comparison to the control group.

\section{IGF-I stimulates its own secretion in the presence of EGF}

In previous studies, we found that IGF-I induced neuronal differentiation (Arsenijevic and Weiss, 1998) and was able to do so by the rapid (2-6 hr) activation of a genetic program mediated, in part, by the transcription factor Brn-4 (Shimazaki et al., 1999). In these studies, the very short exposure to IGF-I (2-24 hr) was sufficient to allow for complete neuronal differentiation that continued for days after the removal of IGF-I. In line with such an action, we hypothesized that a transient exposure to IGF-I may also induce a program in NSCs that would permit mitogens to activate proliferation. Thus, we examined the results of shortterm exposures to IGF-I on NSC proliferation. In the first series of experiments, we found that IGF-I stimulation as short as $24 \mathrm{hr}$, in the constant presence of EGF, was sufficient to produce a sphere number comparable with those generated during a continuous co-incubation of IGF-I and EGF for 8 DIV (Fig. 6). On the other hand, a $24 \mathrm{hr}$ exposure to IGF-I did not support NSC proliferation in the presence of FGF-2 $(n=5)$, in comparison to
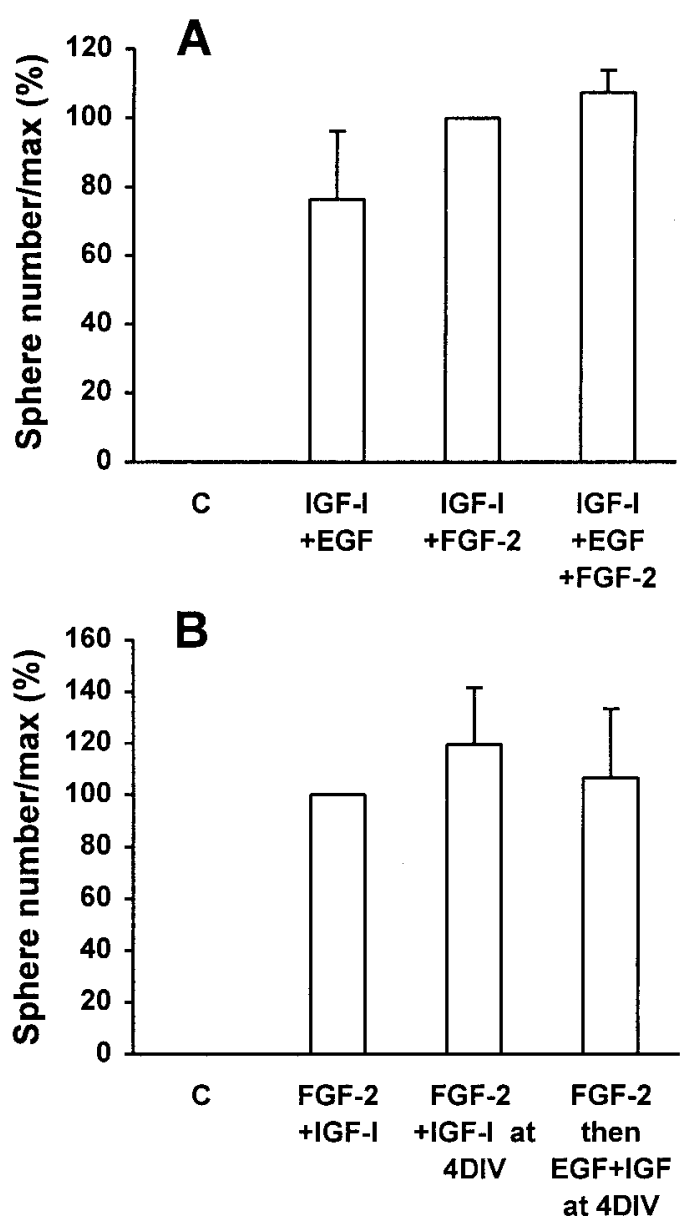

Figure 5. EGF and FGF-2 are both acting on the same stem cells. $A$, To know whether IGF-I, EGF, and FGF-2 are acting on the same cells in our culture conditions ( 5000 cells per well), the additive action of these factors was tested. We have arbitrarily chosen IGF-I + FGF-2-generated sphere number as the reference group. No significant differences were observed between the groups. Note that no additive action of IGF-I, EGF, and FGF-2 was observed $(n=5)$. $B$, To confirm these results, the action of FGF-2 on survival or the maintenance of the NSC state was assayed on EGF-responsive stem cells. Substitution of FGF-2 by EGF + IGF-I at 4 DIV gave rise to a similar number of spheres in comparison to cells stimulated by FGF-2 and IGF-I constantly (second column) or starting at 4 DIV (third column). Note that FGF-2 acts as a survival factor or maintains NSC state for both FGF-2- and EGF-responsive stem cells. $C$, Control culture without factors.

NSC coactivation for the entire period. The latter result demonstrates a unique cooperative action of IGF-I with EGF and also excludes an incomplete wash as explaining the success of transient IGF-I with continuous EGF. Thus, the continuous presence of IGF-I is not necessary for EGF-stimulated NSC proliferation, and it is possible that an intracellular or transcription event induced by the short exposure to IGF-I can maintain the proliferative action of EGF. To confirm that a rapid induction may be the case, we reduced IGF-I exposure time to a stimulation of $2 \mathrm{hr}$. After only $2 \mathrm{hr}$ of transient IGF-I exposure, $85 \%$ of NSCs could be induced to proliferate in the continuous presence of EGF. In parallel experiments, we found that the spheres generated by short exposure to IGF-I and continuous EGF exhibited a virtually identical pattern of renewal and multipotentiality (data not shown) as seen with spheres that were generated in continuous co-incubation (Table 1). 


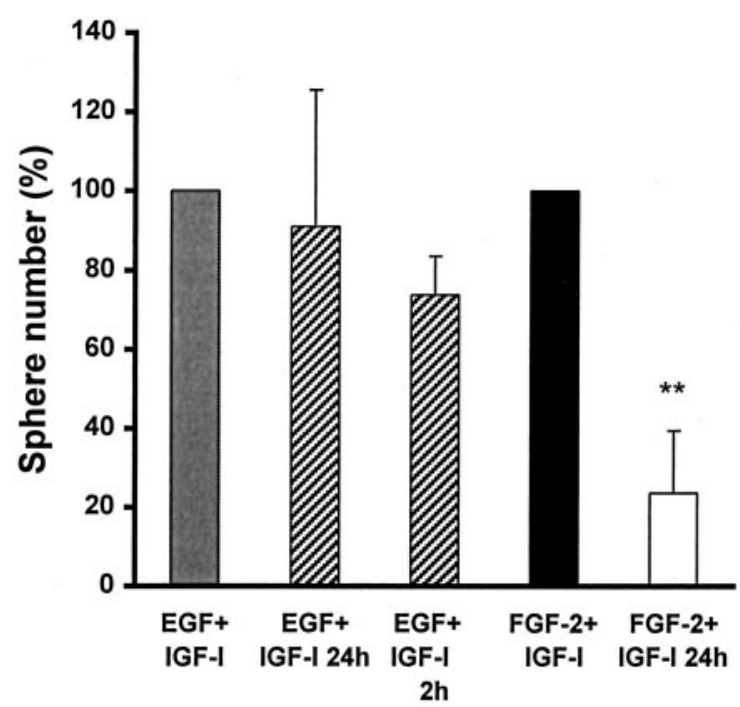

Figure 6. Short exposure to IGF-I is sufficient to induce NSC proliferation in the presence of EGF, but not of FGF-2. Striatal cells from mouse E14 embryos were stimulated with EGF for up to 10 DIV. During EGF treatment, groups of cells received various time exposures of IGF-I: 10 DIV, $24 \mathrm{hr}$, or $2 \mathrm{hr}$. Only cells that were stimulated with IGF-I induced sphere formation. No significant differences in sphere numbers were observed between long- and short-term ( 24 and $2 \mathrm{hr})$ stimulation with IGF-I (second and third columns, $p=0.78$ ). Short exposure of IGF-I during the constant presence of FGF-2 rarely generated spheres $(n=5$; $* * p<0.01)$.

These findings suggest that the synergistic actions of IGF-I and EGF on NSCs involve a unique function or mechanisms. Such actions were not apparent in the combined actions of IGF-I and FGF-2 on NSCs. One potential mechanism for the sustained action of IGF-I, after its transient exposure to NSCs, would be through an EGF-dependent autocrine-paracrine release during subsequent sphere formation. In fact, such an action underlies the sustained action of transient IGF-I on neuronal differentiation (Shimazaki et al., 1999). Thus, we added neutralizing antibodies to IGF-I (Shimazaki et al., 1999) at the end of a $24 \mathrm{hr}$ IGF-I exposure and wash. During the subsequent continuous exposure to EGF, we observed an $85 \pm 12.3 \%(n=4 ; p=0.0002)$ decrease in sphere formation in comparison to the group incubated with control IgG. These results indicate that IGF-I is endogenously synthesized after a transient exposure to IGF-I and acts, in part, to sustain continuous NSC proliferation by EGF. This observation further underscores, at the cellular level, the continued physiological requirement of IGF-I for NSC proliferation.

\section{DISCUSSION}

The present work demonstrates that IGF-I is necessary for mouse embryonic striatal NSC proliferation and that IGF-I acts synergistically with EGF or FGF-2. It also appears that IGF-I, EGF, and FGF-2 have distinct actions in the control of NSC state and proliferation.

\section{IGF-I is necessary for brain growth and neural stem cell proliferation}

Numerous studies revealed a pleiotropic action of IGF-I during neurogenesis (de Pablo and de la Rosa, 1995; Ishii, 1995). However, no action of IGF-I on CNS stem cells has been reported. Both during development and adulthood, IGF receptors and ligands of IGF are present in the germinal zone as well as in the subventricular zone (SVZ) (see the introductory remarks), sup- porting the potential role of IGF-I in the in vivo regulation of NSCs. In the present study, IGF-I was shown to regulate the number of NSCs. If the number of proliferating NSCs depends on IGF-I, it is reasonable to suggest that the final number of neural cells should depend on the concentration of IGF family peptides during brain development. This hypothesis is supported by brain development in mice with null mutations of the IGFs or the IGF-I receptor. All of these mutant mice have significant deficits in body and brain development (Baker et al., 1993; Liu et al., 1993; Beck et al., 1995). Our results show that IGF-I is necessary for the activation of FGF-2-responsive NSCs, which can be isolated as early as E8.5 (Tropepe et al., 1999). Studies of FGF-2 knock-out mice revealed that FGF-2 is essential for normal brain development (Deng et al., 1994; Yamaguchi et al., 1994) before the period where IGF-I/II play an important role in brain-body development (Baker et al., 1993; Liu et al., 1993). These results suggest that FGF-2-responsive NSCs are likely controlled by another factor besides IGF-I. Insulin is one good candidate, because its secretion and subsequent biological action occurs throughout embryonic development. However, during later embryonic development, IGF-I seems to be of critical importance for brain formation. A deficiency in IGF-I produces a delay of growth detectable at E13.5 (Baker et al., 1993), a time when EGF receptors play a significant role in brain development, as attested by the morphology of the CNS in EGF receptor-deficient mice (Sibilia et al., 1998). During this period of CNS development, there is a striking correlation between the temporal needs of both EGF and IGF-I. Moreover, a more detailed analysis of IGF-I $(-/-)$ mice showed that the brain is reduced in size and that a specific population of neurons is missing in the striatum (Beck et al., 1995); the latter observation is in accordance with the role of IGF-I as a differentiating factor on striatal neural precursors (Arsenijevic and Weiss, 1998; Shimazaki et al., 1999).

The present IGF-I immunoneutralization study reveals that a source of IGF-I may also be the NSC itself, revealing that IGF-I is endogenously involved, at the cellular level, in the control of NSC proliferation. An autocrine secretion occurs after costimulation of EGF and IGF-I. These observations further support the tight link between EGF and IGF-I in the control of NSC proliferation, as discussed above. EGF is present during the period of development that sees dramatic increases in brain size. From our study, it appears that EGF and IGF-I may participate in a positive feedback loop for the expansion of NSCs. Such mechanisms may operate during the late brain growth phase to accelerate brain organogenesis. A negative control of IGF-I action seems also to occur during this period of development and during adulthood. Different types of IGF-I binding proteins (IGFBPs) are known to enhance or inhibit IGF-I action depending on the cellular context (Murphy, 1998). Studies of IGFBPs during brain development (Bondy and Lee, 1993; Green et al., 1994) reveal that IGFBP-5 may have a role related to NSCs. Messenger RNA for IGFBP-5 is first detected at E10.5 in the neuroepithelium (Green et al., 1994). High levels of IGFBP-5 mRNA persist in the SVZ from postnatal day (P) 0 to at least P20 (Bondy and Lee, 1993). These results suggest that the action of IGF-I on stem cells could be regulated by at least one member of the IGFBP family, during the later stages of brain development as well as during adulthood, thus enhancing the potential physiological role of IGF-I on NSC regulation.

Mouse null mutation studies have revealed a dependence on IGF-I, FGF-2, and EGF for brain growth, but have not demonstrated specific functions for each of these growth factors. In the 
present study, FGF-2 clearly has an important action on NSC survival or on the maintenance of the stem cell state. A survival action of FGF-2 on PNS and CNS neurons has been demonstrated (Unsicker et al., 1987; Walicke, 1988; Fontaine et al., 1998; Krieglstein et al., 1998). Our results contrast with those of Drago et al. (1991), who reported that IGF-I acted as a survival factor for an FGF-2-responsive progenitor cell that gave rise to neurons and glia. However, at the time of the latter study, the hierarchical relationship between that progenitor cell and NSCs was not clearly established, and thus the progenitor cell could be different from the NSCs studied here. The progenitor cell described in the Drago et al. (1991) study might be a more downstream-restricted precursor cell, such as that described by Vescovi et al. (1993). An alternative interpretation of our findings is that FGF-2 maintains NSCs in an undifferentiated state. This would imply that, in the absence of these growth factors NSCs differentiate to a nonproliferative (sphere-forming) state. In this hypothesis, FGF-2 would be the only factor that, in comparison to IGF-I or EGF, is able to maintain NSC characteristics. Interestingly, in the absence of exogenous growth factors that support proliferation, FGF-2 is endogenously secreted by retinal stem cells to induce their proliferation (Tropepe et al., 2000). It is not clear whether the lack of FGF-2 induces cell death or differentiation of retinal stem cells. Manipulation of IGF-I and FGF-2 in this system may allow further light to be shed on the precise function of FGF-2.

Only with the addition of EGF could IGF-I support both proliferation and survival of NSCs. Interestingly, FGF-2, EGF, or IGF-I alone did not have a mitogenic action; rather a combination was required to stimulate NSC proliferation. This is in contrast to other biological systems in which, for example, either FGF-2 or IGF-I alone can have an in vitro mitogenic action on $\mathrm{C} 2 \mathrm{C} 12$ myoblasts (Milasincic et al., 1996), vascular smooth muscle cells (Reape et al., 1996), and inner ear epithelial cells (Zheng et al., 1997). In the latter two cases, combinations of the growth factors have a synergistic effect on cell proliferation (Reape et al., 1996; Zheng et al., 1997). Thus, the cooperative actions of IGF-I with either EGF or FGF-2 in NSC proliferation is rather unique as regards mitogenesis and may speak for the need for exquisite control of this vital process. On the other hand, the precise role for each factor in NSC cycle regulation remains to be determined.

\section{One or two neural stem cells?}

The existence of EGF- and FGF-2-responsive stem cells opens the question of their lineage relationships. Several studies have addressed whether two different NSCs exist or whether the telencephalon contains one NSC that responds to the two different growth factors (Ciccolini and Svendsen, 1998; Gritti et al., 1999; Tropepe et al., 1999). The recent work by Tropepe et al. (1999) revealed that at low cell culture density, EGF and FGF-2 have additive actions on E14.5 NSCs, but this was not observed at high cell culture density. These results suggest that two populations of NSCs exists and that yet another factor controls NSC proliferation or survival. In contrast, studies either with B27 as an NSC survival mixture (Ciccolini and Svendsen, 1998) or with adult tissue (Gritti et al., 1999) suggest that a unique NSC is present in the forebrain. The difference in methods between these studies makes reconciling the data difficult. Our results suggest that FGF-2 acts as a survival factor for a single population of E14 EGF- and FGF-2-responsive NSCs. In the study by Tropepe et al. (1999), the influence of cell density on the generation of NSCs is more significant for the actions of EGF than for those of FGF-2; a high cell density allowed for a more elevated number of NSCs after EGF stimulation. The evidence for two NSC populations could be biased by the relative difference in survival actions of FGF-2 and EGF. Thus, at low cell density, the survival of NSCs is not optimum and the frequency of sphere formation depends both on the mitogenic and the survival actions of the factors tested. Ultimately, a thorough understanding of the factors that regulate survival and/or proliferation of NSCs will be necessary for reconciling whether there are single versus multiple NSC populations in the forebrain.

\section{EGF and FGF-2 have distinct actions on neural stem cells}

A principal conclusion derived from the present data is that EGF and FGF-2 have distinct actions on striatal NSCs. These include the control of survival or NSC state and the stimulation threshold producing a biological action. As discussed above, FGF-2 has a significant action on NSC survival or state. The fact that EGF does not show this function indicates that the downstream effectors of EGFR and the FGFR-1 are likely different, as regards the control of the NSC state. A similar conclusion may be drawn concerning the transduction pathway of EGFR compared with that of FGFR-1 in relation to the activation of the IGF-I receptor. Indeed, a short stimulation by IGF-I in the constant presence of EGF was able to stimulate NSC proliferation, a biological effect not observed with FGF-2. Together, it appears that NSCs possess multiple levels of controls and distinct intracellular mechanisms to regulate their state and proliferation. The actions of EGF and FGF-2 are likely not fully redundant, but rather complementary as well. Also, different intracellular pathways control the stimulation of NSCs, presumably to integrate signals from various cell environments. The regulation of NSC stimulation may be even more complex. Indeed, for adult hippocampal NSCs, FGF-2 is not sufficient even in the presence of IGF-I to control cell division (Taupin et al., 2000). The glycosylated form of cystatin was found to be necessary along with FGF-2 to activate the proliferation and the expansion of adult hippocampal NSCs (Taupin et al., 2000). Again, two cofactors were found necessary for this function. It seems possible that different sets of cofactors regulate NSCs: IGF-I and EGF on one hand, and FGF-2 and cystatin on the other. It would be interesting to test whether these cofactor requirements are inherent to NSCs of different regions and how they are expressed during development and adulthood. Other factors acting on embryonic or adult NSCs, such as TGF $\alpha$ (Tropepe et al., 1997), BMP4 and Noggin (Lillien and Raphael, 2000; Lim et al., 2000), as well as the ephrin family (Conover et al., 2000) are also thought to act directly or indirectly on NSC proliferation. Knowing when and where, during development and adulthood, these factors are required and how they are effective on the various NSCs of the CNS is of prime importance for understanding NSC biology. Similarly, this knowledge is essential for the optimization of in vivo mobilization of NSCs, when attempting to produce the required cell phenotype in specific brain regions as a strategy for neuronal replacement (Craig et al., 1996; Kuhn et al., 1997; Aberg et al., 2000; Fallon et al., 2000).

\section{REFERENCES}

Aberg MA, Aberg ND, Hedbacker H, Oscarsson J, Eriksson PS (2000) Peripheral infusion of IGF-I selectively induces neurogenesis in the adult rat hippocampus. J Neurosci 20:2896-2903.

Ahmed S, Reynolds BA, Weiss S (1995) BDNF enhances the differentiation but not the survival of CNS stem cell-derived neuronal precursors. J Neurosci 15:5765-5778.

Arsenijevic Y, Weiss S (1998) IGF-I is a differentiation factor for post- 
mitotic CNS stem cell-derived neuronal precursors: distinct actions from those of BDNF. J Neurosci 18:2118-2128.

Baker J, Liu JP, Robertson EJ, Efstratiadis A (1993) Role of insulin-like growth factors in embryonic and postnatal growth. Cell 75:73-82.

Bartlett WP, Li X-S, Williams M, Benkovic S (1991) Localization of insulin-like growth factor-1 mRNA in murine central nervous system during postnatal development. Dev Biol 147:239-250.

Bassas L, Girbau M, Lesniak MA, Roth J, de Pablo F (1989) Development of receptors for insulin and insulin-like growth factor-I in head and brain of chick embryos: autoradiographic localization. Endocrinology 125:2320-2326.

Beck KD, Powell-Braxton L, Widmer HR, Valverde J, Hefti F (1995) Igf1 gene disruption results in reduced brain size, CNS hypomyelination, and loss of hippocampal granule and striatal parvalbumincontaining neurons. Neuron 14:717-730.

Ben-Hur T, Rogister B, Murray K, Rougon G, Dubois-Dalcq M (1998) Growth and fate of PSA-NCAM+ precursors of the postnatal brain. J Neurosci 18:5777-5788.

Bondy C, Lee WH (1993) Correlation between insulin-like growth factor (IGF)-binding protein 5 and IGF-I gene expression during brain development. J Neurosci 13:5092-5104.

Bondy CA (1991) Transient IGF-I gene expression during the maturation of functionally related central projection neurons. J Neurosci 11:3442-3455.

Bondy CA, Werner H, Roberts Jr CT, LeRoith D (1990) Cellular pattern of insulin-like growth factor-I (IGF-I) and Type I IGF receptor gene expression in early organogenesis: comparison with IGF-II gene expression. Mol Endocrinol 4:1386-1398.

Burrows RC, Wancio D, Levitt P, Lillien L (1997) Response diversity and the timing of progenitor cell maturation are regulated by developmental changes in EGFR expression in the cortex. Neuron 19:251-267.

Ciccolini F, Svendsen CN (1998) Fibroblast growth factor 2 (FGF-2) promotes acquisition of epidermal growth factor (EGF) responsiveness in mouse striatal precursor cells: identification of neural precursors responding to both EGF and FGF-2. J Neurosci 18:7869-7880.

Conover JC, Doetsch F, Garcia-Verdugo JM, Gale NW, Yancopoulos GD, Alvarez-Buylla A (2000) Disruption of Eph/ephrin signaling affects migration and proliferation in the adult subventricular zone. Nat Neurosci 3:1091-1097.

Craig CG, Tropepe V, Morshead CM, Reynolds BA, Weiss S, van der Kooy D (1996) In vivo growth factor expansion of endogenous subependymal neural precursor cell populations in the adult mouse brain. J Neurosci 16:2649-2658.

DeHamer MK, Guevara JL, Hannon K, Olwin BB, Calof AL (1994) Genesis of olfactory receptor neurons in vitro: regulation of progenitor cell divisions by fibroblast growth factors. Neuron 13:1083-1097.

Deng CX, Wynshaw-Boris A, Shen MM, Daugherty C, Ornitz DM, Leder P (1994) Murine FGFR-1 is required for early postimplantation growth and axial organization. Genes Dev 8:3045-3057.

de Pablo F, de la Rosa EJ (1995) The developing CNS: a scenario for the action of proinsulin, insulin and insulin-like growth factors. Trends Neurosci 18:143-150.

Devaskar SU, Singh BS, Carnaghi LR, Rajakumar PA, Giddings SJ (1993) Insulin II gene expression in rat central nervous system. Regul Pept 48:55-63.

Drago J, Murphy M, Carroll SM, Harvey RP, Bartlett PF (1991) Fibroblast growth factor-mediated proliferation of central nervous system precursors depends on endogenous production of insulin-like growth factor I. Proc Natl Acad Sci USA 88:2199-2203.

Fallon J, Reid S, Kinyamu R, Opole I, Opole R, Baratta J, Korc M, Endo TL, Duong A, Nguyen G, Karkehabadhi M, Twardzik D, Loughlin S (2000) In vivo induction of massive proliferation, directed migration, and differentiation of neural cells in the adult mammalian brain. Proc Natl Acad Sci USA 97:14686-14691.

Fontaine V, Kinkl N, Sahel J, Dreyfus H, Hicks D (1998) Survival of purified rat photoreceptors in vitro is stimulated directly by fibroblast growth factor-2. J Neurosci 18:9662-9672.

Garcia-Segura LM, Perez J, Pons S, Rejas MT, Torres-Aleman I (1991) Localization of insulin-like growth factor I (IGF-I)-like immunoreactivity in the developing and adult rat brain. Brain Res 560:167-174.

Garofalo RS, Rosen OM (1988) Tissue localization of Drosophila megalonaster insulin receptor during development. Mol Cell Biol $8: 1638-1647$

Green BN, Jones SB, Streck RD, Wood TL, Rotwein P, Pintar JE (1994) Distinct expression patterns of insulin-like growth factor binding proteins 2 and 5 during fetal and postnatal development. Endocrinology 134:954-962

Gritti A, Frolichsthal-Schoeller P, Galli R, Parati EA, Cova L, Pagano SF, Bjornson CR, Vescovi AL (1999) Epidermal and fibroblast growth factors behave as mitogenic regulators for a single multipotent stem cell-like population from the subventricular region of the adult mouse forebrain. J Neurosci 19:3287-3297.

Gross RE, Mehler MF, Mabie PC, Zang Z, Santschi L, Kessler JA (1996) Bone morphogenetic proteins promote astroglial lineage commitment by mammalian subventricular zone progenitor cells. Neuron $17: 595-606$

Hammang JP, Archer DR, Duncan ID (1997) Myelination following transplantation of EGF-responsive neural stem cells into a myelindeficient environment. Exp Neurol 147:84-95.

Ishii DN (1995) Implication of insulin-like growth factors in the pathogenesis of diabetic neuropathy. Brain Res Brain Res Rev 20:47-67.

Johe KK, Hazel TG, Muller T, Dugich-Djordjevic MM, McKay RDG (1996) Single factors direct the differentiation of stem cells from the fetal and adult central nervous system. Genes Dev 10:3129-3140.

Kalyani A, Hobsen C, Rao M (1997) Neuroepithelial cells from the embryonic spinal cord: isolation, characterization, and clonal analysis. Dev Biol 186:202-223.

Kalyani A, Mujtaba T, Rao M (1999) Expression of EGF receptor and FGF receptor isoforms during neuroepithelial stem cell differentiation. J Neurobiol 38:207-224.

Kar S, Chabot J-G, Quirion R (1993) Quantitative autoradiographic localization of $\left[{ }^{125}\right.$ I]insulin-like growth factor I, $\left.{ }^{125} \mathrm{I}\right]$ insulin-like growth factor II, and [ $\left.{ }^{125} \mathrm{I}\right]$ insulin receptor binding sites in developing and adult rat brain. J Comp Neurol 333:375-397.

Krieglstein K, Reuss B, Maysinger D, Unsicker K (1998) Short communication: transforming growth factor-beta mediates the neurotrophic effect of fibroblast growth factor-2 on midbrain dopaminergic neurons. Eur J Neurosci 10:2746-2750.

Kuhn HG, Winkler J, Kempermann G, Thal LJ, Gage FH (1997) Epidermal growth factor and fibroblast growth factor-2 have different effects on neural progenitors in the adult rat brain. $J$ Neurosci 17:5820-5829.

LeRoith D, Lowe Jr WL, Shemr J, Raizada M, Ota A (1988) Development of brain insulin receptors. Int J Biochem 20:225-230.

LeRoith D, Werner H, Faria TN, Kato H, Adamo M, Roberts Jr CT (1993) Insulin-like growth factors receptors. Ann NY Acad Sci 692:23-32.

Lillien L, Raphael H (2000) BMP and FGF regulate the development of EGF-responsive neural progenitor cells. Development 127:4993-5005.

Lim DA, Tramontin AD, Trevejo JM, Herrera DG, García-Verdugo JM, Alvarez-Buylla A (2000) Noggin antagonizes BMP signaling to create a niche for adult neurogenesis. Neuron 28:713-726.

Liu JP, Baker J, Perkins AS, Robertson EJ, Efstratiadis A (1993) Mice carrying null mutations of the genes encoding insulin-like growth factor I (Igf-1) and type 1 IGF receptor (Igf1r). Cell 75:59-72.

Marmur R, Kessler JA, Zhu G, Gokhan S, Mehler MF (1998) Differentiation of oligodendroglial progenitors derived from cortical multipotent cells requires extrinsic signals including activation of gp130/ LIFbeta receptors. J Neurosci 18:9800-9811.

Mehler MF, Kessler JA (1997) Hematolyphopoietic and inflammatory cytokines in neural development. Trends Neurosci 20:357-365.

Milasincic DJ, Calera MR, Farmer SR, Pilch PF (1996) Stimulation of $\mathrm{C} 2 \mathrm{C} 12$ myoblast growth by basic fibroblast growth factor and insulinlike growth factor 1 can occur via mitogen-activated protein kinasedependent and -independent pathways. Mol Cell Biol 16:5964-5973.

Morshead CM, Reynolds BA. Craig CG, McBurney MW, Staines WA Morassutti D, Weiss S, van der Kooy D (1994) Neural stem cells in the adult mammalian forebrain: a relatively quiescent subpopulation of subependymal cells. Neuron 13:1071-1082.

Murphy LJ (1998) Insulin-like growth factor-binding proteins: functional diversity or redundancy? J Mol Endocrinol 21:97-107.

Palmer TD, Takahashi J, Gage FH (1997) The adult rat hippocampus contains primordial neural stem cells. Mol Cell Neurosci 8:389-404.

Petruzelli L, Herrera R, Arenas-Garcia RA, Fernandez R, Birnbaum MJ, Rosen OM (1986) Isolation of a Drosophila genomic sequence homologous to the kinase domain of the human insulin receptor and detection of the phosphorylated Drosophila receptor with an antipeptide antibody. Proc Natl Aca Sci USA 83:4710-4714.

Qian X, Davis AA, Goderie SK, Temple S (1997) FGF2 concentration regulates the generation of neurons and glia from multipotent cortical stem cells. Neuron 18:81-93.

Qian X, Shen Q, Goderie SK, He W, Capela A, Davis AA, Temple S (2000) Timing of CNS cell generation: a programmed sequence of neuron and glial cell production from isolated murine cortical stem cells. Neuron 28:69-80.

Rao M, Mayer-Proschel M (1997) Glial restricted precursors are derived from multipotent neuroepithelial stem cells. Dev Biol 188:48-63.

Reape TJ, Kanczler JM, Ward JP, Thomas CR (1996) IGF-I increases bFGF-induced mitogenesis and upregulates FGFR-1 in rabbit vascular smooth muscle cells. Am J Physiol 270:H1141-1148.

Reynolds BA, Weiss S (1992) Generation of neurons and astrocytes from isolated cells of the adult mammalian central nervous system. Science 255:1707-1710.

Reynolds BA, Weiss S (1996) Clonal and population analyses demonstrate that an EGF-responsive mammalian embryonic CNS precursor is a stem cell. Dev Biol 175:1-13.

Reynolds BA, Tetzlaff W, Weiss S (1992) A multipotent EGFresponsive striatal embryonic progenitor cell produces neurons and astrocytes. J Neurosci 12:4565-4574. 
Shihabuddin LS, Ray J, Gage FH (1997) FGF-2 is sufficient to isolate progenitors found in the adult mammalian spinal cord. Exp Neurol 148:577-586.

Shimazaki T, Arsenijevic Y, Ryan AK, Rosenfeld MGR, Weiss S (1999) A role for the POU-III transcription factor Brn-4 in the regulation of striatal neuron precursor differentiation. EMBO J 18:444-456.

Sibilia M, Steinbach JP, Stingl L, Aguzzi A, Wagner EF (1998) A strainindependent postnatal neurodegeneration in mice lacking the EGF receptor. EMBO J 17:719-731.

Stylianopoulou F, Herbert J, Soares MB, Efstratiadis A (1988) Expression of the insulin-like growth factor II gene in the choroid plexus and the leptomeninges of the adult rat central nervous system. Proc Natl Acad Sci USA 85:141-145.

Taupin P, Ray J, Fischer WH, Suhr ST, Hakansson K, Grubb A, Gage FH (2000) FGF-2-responsive neural stem cell proliferation requires CCg, a novel autocrine/paracrine cofactor. Neuron 28:385-397.

Tropepe V, Craig CG, Morshead CM, van der Kooy D (1997) Transforming growth factor-a null and senescent mice show decreased neural progenitor cell proliferation in the forebrain subependyma. J Neurosci 17:7850-7859.

Tropepe V, Sibilia M, Ciruna BG, Rossant J, Wagner EF, van der Kooy D (1999) Distinct neural stem cells proliferate in response to EGF and FGF in the developing mouse telencephalon. Dev Biol 208:166-188.

Tropepe V, Coles BL, Chiasson BJ, Horsford DJ, Elia AJ, McInnes RR, van der KD (2000) Retinal stem cells in the adult mammalian eye. Science 287:2032-2036.

Unsicker K, Reichert-Preibsch H, Schmidt R, Pettmann B, Labourdette G, Sensenbrenner M (1987) Astroglial and fibroblast growth factors have neurotrophic functions for cultured peripheral and central nervous system neurons. Proc Natl Acad Sci USA 84:5459-5463.

Vescovi AL, Reynolds BA, Fraser DD, Weiss S (1993) bFGF regulates the proliferative fate of unipotent (neuronal) and bipotent (neuronal/ astroglial) EGF-generated CNS progenitor cells. Neuron 11:951-966.

Walicke PA (1988) Basic and acidic fibroblast growth factors have trophic effects on neurons from multiple CNS regions. J Neurosci 8:2618-2627.

Yamaguchi TP, Harpal K, Henkemeyer M, Rossant J (1994) FGFR-1 is required for embryonic growth and mesodermal patterning during mouse gastrulation. Genes Dev 8:3032-3044.

Zhang SC, Lipsitz D, Duncan ID (1998) Self-renewing canine oligodendroglial progenitor expanded as oligospheres. J Neurosci Res 54:181-190.

Zheng JL, Helbig C, Gao WQ (1997) Induction of cell proliferation by fibroblast and insulin-like growth factors in pure rat inner ear epithelia cell cultures. J Neurosci 17:216-226.

Zhu G, Mehler MF, Mabie PC, Kessler JA (1999) Developmental changes in progenitor cell responsiveness to cytokines. J Neurosci Res 56:131-145 